\title{
Article
}

\section{The Influence of Sociological Variables on Users' Feelings about Programmatic Advertising and the Use of Ad-Blockers}

\author{
Enrique Rus-Arias ${ }^{1}\left[\right.$, Pedro R. Palos-Sanchez ${ }^{2, *}$ (I) and Ana Reyes-Menendez ${ }^{3}([)$ \\ 1 Department of Financial Economics and Accounting, University of Extremadura, 10005 Caceres, Spain; \\ erus@unex.es \\ 2 Department of Financial Economy and Operations Management, Faculty of Economics and Business, \\ University of de Sevilla, Av. de Ramon y Cajal 1, 41004 Sevilla, Spain \\ 3 Department of Business and Economics, Rey Juan Carlos University, Paseo Artilleros s/n, \\ 28032 Madrid, Spain; ana.reyes@urjc.es \\ * Correspondence: ppalos@us.es
}

Citation: Rus-Arias, E.;

Palos-Sanchez, P.R.; Reyes-Menendez,

A. The Influence of Sociological Variables on Users' Feelings about Programmatic Advertising and the Use of Ad-Blockers. Informatics 2021,

8, 5. https://doi.org/10.3390/

informatics 8010005

Academic Editor: Antony Bryant

Received: 28 November 2020

Accepted: 20 January 2021

Published: 27 January 2021

Publisher's Note: MDPI stays neutral with regard to jurisdictional claims in published maps and institutional affiliations.

Copyright: (c) 2021 by the authors. Licensee MDPI, Basel, Switzerland. This article is an open access article distributed under the terms and conditions of the Creative Commons Attribution (CC BY) license (https:/ / creativecommons.org/licenses/by/ $4.0 /)$
Abstract: The evolution of digital advertising, which is aimed at a mass audience, to programmatic advertising, which is aimed at individual users depending on their profile, has raised concerns about the use of personal data and invasion of user privacy on the Internet. Concerned users install ad-blockers that prevent users from seeing ads and this has resulted in many companies using antiad-blockers. This study investigates the sociological variables that make users feel that advertising is annoying and then decide to use ad-blockers to avoid it. Our results provide useful information for companies to appropriately segment user profiles. To do this, data collected from Internet users $(n=19,973)$ about what makes online advertising annoying and why they decide to use ad-blockers are analyzed. First, the existing literature on the subject was reviewed and then the relevant sociological variables that influence users' feelings about online advertising and the use of ad-blockers were investigated. This work contributes new information to the discussion about user privacy on the Internet. Some of the key findings suggest that Internet advertising can be very intrusive for many users and that all the variables investigated, except marital status and education, influence the users' opinions. It was also found that all the variables in this study are important when a user decides to use an ad-blocker. A clear and inverse correlation between age and opinion about advertising as annoying could be seen, along with a clear difference of opinion due to gender. The results suggest that users without children use ad-blockers the least, while retirees and housewives use them the most.

Keywords: programmatic advertising; blocker; anti-blocker; privacy; digital advertising

\section{Introduction}

The rapid evolution of technology in the last few years has dramatically changed the interaction between users and companies. Today, customers depend on the mobile devices that they use to connect to the Internet at any time and from any place [1]. Customers also frequently use mobile devices for daily activities, such as looking for information about products they are interested in or making online purchases [2].

Companies have also become aware of how technology has changed the technological environment. One of the most notable advances is the appearance of Web 2.0 that allows customers and companies to communicate bi-directionally [3] or Internet advertising that enables companies to target users based on their interests [2].

The fact that customers now use their mobile phones for everything and that companies accept the importance of this channel has promoted the growth of online advertising [4], from the so-called traditional marketing [5] to online advertising. However, this has become a massive phenomenon, and companies are now concerned about how to make advertising effective, rather than annoying for customers. An advertising campaign can 
fail if the users do not like it or feel negative about it for any reason [6]. Several studies have analyzed consumer attention to online advertising campaigns and how to attract more customers with them [7].

The negative effects that mass advertising has on the effectiveness of advertising campaigns have resulted in new types of online advertising that are personalized based on the profile of the user. Search engine advertising, known as Search Engine Marketing (SEM), allows advertisers to select profiles of users who will see their messages, because this approach uses the previous searches of a user to select possible future customers [2]. Furthermore, advertising on social platforms allows companies to include segmented advertising messages for specific audiences [8]. Finally, programmatic advertising is a type of online advertising that uses more segmentation than previous approaches [9].

Unlike traditional digital advertising, programmatic advertising is less invasive. However, similar to traditional digital advertising, programmatic advertising has problems due to concerns about data privacy. Therefore, annoying advertising remains a problem for companies and their marketing campaigns. Privacy has remained one of the key concerns for consumers, and the situation has become worse due to the use of social networks such as Facebook and Twitter. Furthermore, empirically some users found all programmatic advertising to be annoying $[4,7,10]$.

The feeling that user privacy can be invaded has caused many users to install adblockers, which prevent them from seeing the advertisements they choose to block. Adblockers are computer programs that allow users to selectively remove adverts from the web pages they visit [11]. Several previous studies have argued that users should be allowed to use ad-blockers, as an advertisement can be morally objectionable, and thus undermine consumer autonomy. However, other authors suggest that the use of adblockers can generate huge losses for companies, with Google being a clear example [12].

Free content on the Internet is monetized with advertising, which clearly makes the use of ad-blockers detrimental for companies and their services [13]. For this reason, the increased use of ad-blockers has resulted in a counteroffensive by companies, which may now use anti-adblockers. As discussed below, these devices allow companies to filter potential customers, preventing access to certain services for users who have adblockers [14].

The main contributions of this work are, first of all, for the users. They are supplied with information that can be used to help them make an informed decision on the aspects which are researched. On the other hand, companies can use the information to evaluate the variables that influence the decisions of these users, allowing them to create more efficient advertising campaigns. Finally, governments and officials can use the information to improve their understanding of data protection rules, in order to improve the regulation of this activity.

The present study aims to investigate the sociological variables that make users feel that advertising is annoying and, as a result, employ programs that block this type of advertising. Identifying these variables is crucial for companies. The remainder of this paper is structured as follows. In Section 2, the most relevant previous studies on digital advertising and ad-blockers are reviewed. In Section 3, the hypotheses which are going to be tested in this study are formulated. Section 4 describes the methodology, Section 5 reports the results of the analysis, the results are then discussed in Section 6, in Section 7 we show the limitations of the study and possible further research is suggested, at least, in Section 8 conclusions are drawn from the findings

\section{Literature Review}

There are different types of online advertising that companies can use. Search engine advertising, known as Search Engine Marketing (SEM), allows advertisers to select the profiles of users who will see their messages [2]. In addition, advertising on social platforms allows companies to include segmented advertising messages for specific audiences [8]. Finally, there is also programmatic advertising, which is a type of online advertising that 
favors greater segmentation than previous approaches and allows companies to increase the effectiveness of their advertising campaigns. All of these types of advertising aim to modify the user's negative feelings about advertising as annoying and, to a certain extent, to prevent users from using ad-blockers.

A systematic literature review was used to find the most interesting articles on this subject for this study [15]. As this is not a review article, but rather an analysis article, the process was simplified by including all articles that dealt with annoying advertising and the use of blockers, and also analyze sociological factors. Those articles that did not include these points were excluded.

The articles were found in two of the most extensive and widely used databases for research, which are the Web of Science (WoS) and Scopus. Duplicated results were eliminated, since Scopus indexes $84 \%$ of the documents published in WoS and WoS duplicates $54 \%$ of those in Scopus $[16,17]$. Articles from only the last five years were taken into account, so that the most up-to-date information possible was used. Some of the most relevant and widely cited articles were also included.

\subsection{Annoying Advertising}

Annoying or intrusive advertising has been studied by various authors and from different perspectives. Some analysed the number of times that a consumer must see an advert before considering it annoying [18]. The results of this study confirmed that traditional advertising requires certain improvements to be fully effective. However, the results gave a maximum number of viewings, after which interest in the advertisement started to drop. Other authors, such as [19], concluded that the feeling that advertising is intrusive gives users a negative attitude to it.

The massive use of personal data has made users increasingly concerned about privacy and the security of their personal data, to the point of considering the continuous bombardment of advertisements too annoying. Several studies concluded that the concern for privacy is directly related to the feeling that programmatic advertising is annoying, which can explain the low impact of this ad-vertising on users [10]. This has been worsened by the changes in the advertising sector itself. Several studies have shown that annoying advertising, due to its ability to attract attention, can actually be more effective in the short term, but its impact and effectiveness considerably decrease in the long term [6].

Other authors, such as [20], analyzed brand recognition as a way to mitigate the negative effects of this type of advertising. For instance, there is evidence that shows that advertising which is considered annoying is effective in increasing brand recognition. The same does not happen with disruptive advertising, which is perceived negatively. Therefore, as recommended by many authors, there should be a balance to avoid the negative effects. The appearance of the so-called "fake news" phenomenon that aims to generate more and more visits to specific websites to monetize clicks must also be mentioned here. This contributed to users rejecting this type of advertising [21].

At this point, it is important to highlight that, while programmatic advertising offers advantages for both companies and consumers, it has several limitations. The main limitation is about privacy and the amount of impact on users [18]. Several studies have analyzed the boundaries between real information and fake news [21-23]. These studies also aimed to identify how users transfer their sensitive data $[24,25]$.

The types of advertising outlined above have been worsened by the proliferation of socalled "fake news" containing false product reviews. In a study of this phenomenon, Some works came to the conclusion that the effect of being seen to be truthful on the Internet was important for users and increased their negative feelings about advertising [26].

Using personal data for aggressive advertising campaigns has become a problem for the privacy of Internet users. Therefore, as highlighted by [22], there is an urgent need to regulate the sectors in which users' personal information is exchanged. 


\subsection{Programmatic Advertising; What It Is and Why It Appears}

Advertising being considered annoying by users has made companies try different methods such as using differentiation strategies [8]. This type of personalized advertising is referred to as programmatic advertising, which is defined as a large-scale tender for advertising spaces [9], and is a clear evolution of traditional online advertising. Advertising spaces are assigned based on the profiles of the targeted users and whenever a user installs cookies in their browser, all the necessary information about their profile is provided to a company so that they can be selected or not [27].

In a comparative study of programmatic advertising and traditional online advertising [9], found that the former has a series of advantages over the latter. The authors described a series of premises that must be fulfilled, such as the advertiser must start the segmentation by selecting the user and not the user selecting which advert to see, as in the traditional type of advertising. In this way, it is the company that buys a space based on the audience it wants to target.

Programmatic advertising is interested in the user, rather than the medium [4]. Therefore, while SEM or Social Ads aim to receive economic profit from advertisements targeted at all customers who use search engines or social networks, in programmatic advertising, the central target is the user according to [27]. This approach has been a revolution in the industry. This new way for a company to interact with the user involves the management of huge amounts of data and enables precise segmentation that can predict the moment when the receiver of the advertisement is most likely to click on it. This produces more effective and efficient marketing campaigns and a greater return on investment. A clear example is search engines like Google, which is used by almost $80 \%$ of users and has this type of segmented advertisements [4].

The programmatic advertising strategy is concerned with giving the content to the right audience (push), whereas traditional online advertising attracts users towards content (pull). Programmatic advertising and traditional online advertising also differ about the data, which is more important for the former and less important for the latter [9]. Programmatic advertising, although adapted to the tastes of users, involves the massive use of personal data. This requires appropriate segmentation and a thorough analysis of user profiles, which raises concerns about user privacy. Users tend to find this type of advertising invasive and take measures to counteract it [4].

\subsection{Adblockers: A Response to Annoying Advertising}

Users have started to respond to aggressive marketing campaigns. One of the most effective measures is to use advertising blockers. Some studies considers that users see digital advertising as the cost of viewing certain content [28]. However, when advertising is aggressive and annoying, users start using ad-blockers. For instancean investigation found that $73 \%$ of respondents aged between 25 and 34 years old knew about ad-blockers and $45 \%$ used them regularly, [4]. The use of ad-blockers has both legal and economic consequences.

Ad-blockers are a kind of computer program that allow users to selectively remove ads from the web pages they visit [11]. Some of the most widely used ad-blockers are Adblock Plus, Adguard, Blur, Disconnect, Ghostery, and uBlock. All of these use a system of filtering where the user decides what type of advertising they want to receive depending on their preferences. All other advertising is blocked. The effectiveness of ad-blockers varies considerably [29]. Other work found a set of web traffic features that identify services that intrude on privacy [30]. Using these characteristics, an automatic system learns the properties of the advertising and services listed by existing blacklists and proposes new services for inclusion in blacklists.

The use of ad-blockers endangers programmatic advertising and the benefits it offers to companies and users. Therefore, various studies have defended these ad-blockers, as opposed to others that have criticized them $[2,4,11]$. Several previous studies have argued that users should be granted the right to use ad-blockers, as an advertisement can be 
morally objectionable, and thus undermine consumer autonomy. However, other authors have suggested that the use of ad-blockers can generate huge losses for companies [12].

Malloy et al [2] used a sample of 2 million users and a large number of web pages with different publishers and advertisements. The results of the study demonstrated that, despite installing ad blockers, users are still exposed to a large number of adverts. Other authors argued that blocking advertisements is the same as avoiding them, and that this does not harm anyone and therefore, it is morally valid [11]. On the other hand, the transfer of these types of data can lead to the manipulation of citizens by economic and political powers [31]. As stated by [32], the use of ad-blockers is the best choice for a large number of users, as there are more users of blockers than advertisers.

The detractors of ad-blockers raised a series of objections about their use. Most of these objections were about monetary aspects, as well as the possible damage to other types of user protection. It should be noted that free content on the Internet is monetized with advertising, which makes the ad-blocker clearly detrimental to these companies and their services [13]. According to [14], the aim should be to find a balance between non-invasive advertising and protecting user privacy, so that the use of ad-blockers is reduced.

Problems caused by ad-blockers to the effectiveness of marketing campaigns have led many companies to use anti-ad blockers, which prevent access to content for users who have these programs installed. According to [14], the aim should be to find a balance between non-invasive advertising and protecting user privacy, so that the use of ad-blockers is reduced. There seems to be a relationship between advertising and ad-blockers. Studying the variables that influence users to consider advertising as annoying can also provide information about the use of ad-blockers.

The articles above show that companies are concerned about the use of adblockers $[2,30]$, the danger of reducing the effectiveness of advertising campaigns when using them [4], and the actions taken by companies to combat the use of ad-blockers [14].

\section{Research Hypotheses}

The main aim of this research is to identify the influence of sociological factors on users when evaluating online advertising and when deciding to use ad-blockers.

\subsection{Research Hypotheses. Sociological Variables}

A set of hypotheses were formulated using the articles found in the literature review above and were then tested. The two key variables were (1) feeling that an advertisement is annoying and (2) using ad-blockers to avoid seeing advertisements. The sociological variables used in this study were the following, age, gender, marital status, occupation, education, number of under-age children and household size. The choice of variables was made using previous research that had found these variables to be important when determining user attitudes to digital advertising.

The hypotheses were tested using the null hypothesis approach, in which the sociodemographic variables are not expected to make any significant differences to the users' feelings about advertising as annoying or when deciding to use ad-blockers. If any significant differences are found, the sociodemographic variable is considered to influence the user. The direction of the significant relationships was found from the relative frequencies and correlations. The hypotheses tested in this study are based on previous research.

\subsubsection{Age}

Some works showed that age has an inverse influence when evaluating advertisements [33]. This means that younger people tended to feel less negative about advertising. Another study concluded that adults were more interested in digital signage, a form of advertising, than young people [34]. Young people were reported to use ad-blockers less than older people [28,35]. The following hypotheses were formulated using this information:

Hypothesis 1 (H1). Young people consider advertising annoying. 
Hypothesis 2 (H2). Young people use ad-blockers less than older people.

\subsubsection{Gender}

Gender also seems to be important when assessing programmatic advertising [33]. For instance, several studies found that men feel that advertising is annoying and try to avoid it [36,37]. No studies were found about ad-blockers. The hypotheses for this study are as follows:

Hypothesis 3 (H3). Men consider advertising more annoying than women do.

Hypothesis 4 (H4). Gender conditions the decision to use ad blockers.

\subsubsection{Education}

As suggested by several studies such as [35], another important factor that influences the user's feeling that advertising is annoying is their level of education. One of the papers reviewed concluded that education influences the amount a user is willing to pay to remove advertising [37]. No research about the use of ad-blockers was found. The hypotheses used in this study are as follows:

Hypothesis 5 (H5). People with a higher educational level consider advertising more annoying.

Hypothesis 6 (H6). Level of education influences the use of ad-blockers.

\subsubsection{Occupation}

With regard to occupation, one study concluded that employed people used more digital media than others, which means that they are more prone to invasive advertising [35]. Employed people have more purchasing power and this was found to influence the amount a user was willing to pay to remove advertisements [37]. No research was found about the use of ad-blockers. The hypotheses used in this study are as follows:

Hypothesis 7 (H7). People with a job perceive advertising as annoying more than the rest of the population.

Hypothesis 8 (H8). Occupation influences the use of ad blockers.

\subsubsection{Underage Children and Household Size}

No research was found which was directly related to the rest of the variables analyzed in this study. The hypotheses used for these in this study were:

Hypothesis 9 (H9). Having underage children influences whether advertising is considered annoying.

Hypothesis 10 (H10). Having underage children influences the use of ad blockers.

Hypothesis 11 (H11). The size of the household influences whether advertising is considered annoying.

Hypothesis 12 (H12). The size of the household influences the use of ad blockers.

\section{Materials and Methods}

The scale used to measure privacy and use of ad-blockers was adapted from previous studies. The measurement scale used by $[38,39]$ was adapted to measure the effect that programmatic advertising on online platforms has. The scale used by [40] was adapted to analyze the influence of a construct on how a user feels about advertising. For both variables, the items were measured on a 5 -point Likert scale $(1=$ "totally disagree", $5=$ "totally agree"). 
Data from the "Internet users 2019" report published by the Spanish Association for Media Research [41] were used in the analysis. AIMC, a non-profit organization carries out audience studies for the Spanish media. It periodically publishes the General Media Study (EGM) in Spain. The data sources used in this study are open and publicly accessible and, therefore, are useful empirical research. The profiles of Internet users with different habits for dealing with digital advertising and the use of ad-blockers were analyzed in this study.

The target audience consisted of visitors to Spanish websites. The data were obtained from non-probabilistic sampling with self-administered questionnaires. The participants were self-selected, as we analyzed the profiles of users who were willing to collaborate. To invite users to participate in the study, banners linked to the online questionnaire were placed on different websites, including regional Spanish institutions, associations, mainstream media, the AIMC website, as well as on social networks such as Facebook and Twitter. The users responded to questionnaires between October and December 2019. The high participation rate indicated that Internet users are very interested in this type of study. Table 1 provides further information about the data collected for the study.

Table 1. Research fact sheet, 2019.

\begin{tabular}{ll}
\hline Fact Sheet & \\
\hline Target audience & Internet users using Spanish websites \\
Collection dates & From 15 October to 9 December 2019 \\
Sample size & 21,003 questionnaires, 19,973 final questionnaires \\
Confidence level & $95 \%$ \\
Sample error & $\pm 3 \%$ \\
\hline Source: Authors using data from the survey of Internet users [41].
\end{tabular}

\subsection{Variables}

The variables which were used in the research hypotheses of the present study were taken from the complete questionnaire [41]. The dependent variables were the evaluation of advertising by users, which was measured on a 5-point Likert-type scale $(1=$ very negative to 5 = very positive. The use of ad-blockers was broken down into three groups, which were people who did not use them, people who use them occasionally, and people who use them frequently. The independent variables were age, education, gender, underage children, occupation, and household size.

\subsection{Descriptive Analysis of the Sample}

Table 2 summarizes the demographic characteristics of the participants in the study. Most respondents were men aged between 35 and 54 years old, either single or married. Most participants were employed, and over $90 \%$ had secondary or university education. Most respondents answered that they had no underage children. Almost 55\% of the respondents were employed in a company. The self-employed respondents were only $10 \%$ of the sample, followed by retirees, students, and the unemployed. The highest percentage of respondents lived in households with between three and five members.

Table 3 shows further details about the age of the participants in the research groups. A descriptive analysis of the participants' ages was made. Dispersion, position, and form were calculated. The normality could then be investigated using these values [42]. The average age was 43 years old, but there was high variability, as shown by the variation coefficient of close to $30 \%$ (see Table 3 ). 
Table 2. Demographic characteristics of the participants $(n=19,973), 2019$.

\begin{tabular}{|c|c|c|}
\hline Items & Frequency & $\%$ \\
\hline \multicolumn{3}{|l|}{ Age } \\
\hline 14-19 & 2733 & $13.68 \%$ \\
\hline $20-24$ & 3176 & $15.90 \%$ \\
\hline $25-34$ & 4937 & $24.72 \%$ \\
\hline $35-44$ & 5067 & $25.37 \%$ \\
\hline $45-54$ & 2812 & $14.08 \%$ \\
\hline $55-64$ & 1248 & $6.25 \%$ \\
\hline \multicolumn{3}{|l|}{65 or more } \\
\hline \multicolumn{3}{|l|}{ Sex } \\
\hline Male & 13,541 & $67.80 \%$ \\
\hline Female & 6432 & $32.20 \%$ \\
\hline \multicolumn{3}{|l|}{ Education } \\
\hline No education & 122 & $0.61 \%$ \\
\hline Primary & 1220 & $6.11 \%$ \\
\hline Secondary & 8644 & $43.28 \%$ \\
\hline University & 9956 & $49.85 \%$ \\
\hline n.a. & 31 & $0.16 \%$ \\
\hline \multicolumn{3}{|l|}{ Occupation } \\
\hline Self employed & 2454 & $12.29 \%$ \\
\hline Employed & 10,978 & $54.96 \%$ \\
\hline Student & 2355 & $11.79 \%$ \\
\hline Housework & 553 & $2.77 \%$ \\
\hline Unemployed & 1386 & $6.94 \%$ \\
\hline Retired and others & 2211 & $11.07 \%$ \\
\hline n.a. & 36 & $0.18 \%$ \\
\hline \multicolumn{3}{|l|}{ Underage children } \\
\hline None & 13,772 & $68.95 \%$ \\
\hline One & 3470 & $17.37 \%$ \\
\hline Two & 2251 & $11.27 \%$ \\
\hline Three & 370 & $1.85 \%$ \\
\hline Four or more & 84 & $0.42 \%$ \\
\hline n.a. & 26 & $0.13 \%$ \\
\hline \multicolumn{3}{|l|}{ Household size } \\
\hline None & 2044 & $10.23 \%$ \\
\hline One & 5489 & $27.48 \%$ \\
\hline Two & 5274 & $26.41 \%$ \\
\hline Four & 5099 & $25.53 \%$ \\
\hline Five & 1329 & $6.65 \%$ \\
\hline Six or more & 721 & $3.61 \%$ \\
\hline n.a. & 17 & $0.09 \%$ \\
\hline
\end{tabular}

Source: Authors using data from the AIMC (2019) survey of Internet users.

Table 3. Descriptive analysis of age, 2019.

\begin{tabular}{ll}
\hline Statistics & Age \\
\hline Number of readings & 19,973 \\
Average & 43 \\
Median & 43 \\
Standard deviation $(\mathrm{n}-1)$ & 13 \\
Coeff. Var. & $29.74 \%$ \\
\hline
\end{tabular}

Source: Authors using data from Internet Users (AIMC, 2019).

The data were grouped into intervals for a more accurate analysis of the distribution of ages. This categorization also allowed the hypotheses to be analyzed with non-parametric tests, as normality was not confirmed. Using the results of the descriptive analysis of age 
(Table 3), most of the data was found to be close to the mean and the median. Therefore, most values were between 25 and 64 years old, especially in the interval between 35 and 54 years.

\subsection{Normality Tests and Hypothesis Testing}

A descriptive analysis of the skewness and kurtosis coefficients was made to study the normality of the age variable. Shapiro-Wilk (SW) statistics are considered to be the most suitable tools when studying large samples [43].

Non-parametric hypothesis testing was chosen as the method to test the different independent sociological variables with the dependent ones for advertising and adblockers $[44,45]$. The reason was that all the analyzed variables were ordinal or nominal except for age, which was converted into ordinal before the analysis. Therefore, the nonparametric U-Mann-Whitney (U) statistic was used to compare two independent groups.

However, the Kruskal-Wallis test $(\mathrm{H})$ was considered the most appropriate for the independent constructs (other sociological variables). When comparing several groups with significant differences, a two-by-two post hoc contrast with the Kruskal Wallis statistic is used.

To check the possible associations between the dependent and independent variables, the Tau-b (T_b) [46] and the Rho of Spearman (R_s) $[47,48]$ were calculated.

As in previous studies [49], several measures were taken to avoid the bias which is common in this type of questionnaire. First, the confidentiality of the respondents was guaranteed so that they could respond honestly. In addition, the questions were asked using very familiar terms. Finally, questions were presented in random order. After collecting the data, Harman's unique factorial test was performed to evaluate the so-called common bias $[50,51]$. The test did not detect any factor that could explain most of the total variance, suggesting that it was very unlikely.

\section{Results}

\subsection{Normality Study}

As discussed in the previous section, all variables except age were classified as nominal and ordinal and, therefore, the appropriate contrast tests were non-parametric. However, age was an important variable to consider. For that reason, the normality of the age variable had to be investigated before deciding which statistic to use (see Table 4).

Table 4. Coefficient of asymmetry and kurtosis, normality tests for age, 2019.

\begin{tabular}{ll}
\hline N. of observations & 19,973 \\
Coeff. of Asymmetry & 0.14 \\
Coeff. of Kurtosis & -0.35 \\
Shapiro-Wilk & $0.000<0.05$ \\
\hline
\end{tabular}

Source: Authors using data from [41].

The asymmetry and kurtosis coefficients was used to study the normality of the age variable. This coefficient was positive and close to zero. The kurtosis coefficient had a negative value, which meant that the distribution was platykurtic. However, the normality tests of Shapiro-Wilk were not significant $(p \geq 0.05)$ and, it could therefore be concluded that the distribution was not normal. Consequently, the variables were grouped into intervals and non-parametric tests were used.

As the condition for normality was not met (sig. $<0.05)$, the age variable was transformed into an ordinal one using class intervals, which are easier to interpret with a large amount of data [42]. To avoid, as far as possible, the loss of information, the data for the age variable were grouped into the largest number of intervals possible.

\subsection{Hypothesis Testing and Post Hoc Tests: Global Hypothesis Test}

A hypothesis test and a post hoc test were used to find which of the sociological variables were significant and how they were related to the independent variables. Correlation tests were also performed. 
The first step was to find which of the sociological variables were significant for deciding whether Internet advertising is annoying and using ad-blockers to avoid advertising (see Table 5). The results showed that only one variable (education) did not influence the user when deciding if advertising is annoying $(p \geq 0.05)$. All the analyzed variables were found to significantly influence the use of ad-blockers.

Table 5. Impact of variables when deciding if advertising is annoying and the use of blockers, 2019.

\begin{tabular}{llllll}
\hline Indep.V./Dep.V. & Back Testing & Sig. Annoying ads & Interpretation & Sig.Ad Blockers Use & Interpretation \\
\hline Age & Kruskal-Wallis & 0.000 & Reject Ho & $0.00 \%$ & \\
Education & Kruskal-Wallis & 0.846 & Support Ho & $0.00 \%$ & Reject Ho \\
Gender & U-Mann-Whitney & 0.000 & Reject Ho & $0.0 \%$ & Roject Ho \\
Underage children & Kruskal-Wallis & 0.000 & Reject Ho & $0.00 \%$ & Reject Ho \\
Occupation & Kruskal-Wallis & 0.000 & Reject Ho & $0.00 \%$ & Reject Ho \\
Household size & Kruskal-Wallis & 0.000 & Reject Ho & $0.00 \%$ & Reject Ho \\
\hline Source & & & &
\end{tabular}

Source: Authors using data from [41].

\subsection{Post Hoc Test and Correlation for the Evaluation of Advertising}

Post hoc hypothesis tests and correlation analysis were performed. The latter was carried out for the independent variables of the ordinal type (see Table 6).

Table 6. User Evaluation of Advertising, 2019.

\begin{tabular}{|c|c|c|c|c|c|c|c|c|c|c|}
\hline Variable & Very Negative & Negative & Middle Value & Positive & Very Positive & KW Post Hoc & Value & Correlation & Value & Sig. \\
\hline \multicolumn{11}{|l|}{ Age } \\
\hline $14-24$ & $20.34 \%$ & $26.05 \%$ & $35.53 \%$ & $11.38 \%$ & $6.70 \%$ & $25-34$ у $35-44$ & 0.289 & Tau-b Kendall & -0.102 & 0.000 \\
\hline $55-64$ & $33.39 \%$ & $31.29 \%$ & $30.30 \%$ & $3.27 \%$ & $1.71 \%$ & \multirow{2}{*}{$55-64$ y más 65} & 0.583 & \multirow{2}{*}{ Rho Spearman } & \multirow{2}{*}{-0.139} & \multirow[t]{2}{*}{0.000} \\
\hline More than 65 & $32.61 \%$ & $34.38 \%$ & $28.29 \%$ & $3.37 \%$ & $1.28 \%$ & & & & & \\
\hline \multicolumn{11}{|l|}{ Sex } \\
\hline Male & $30.63 \%$ & $31.99 \%$ & $29.55 \%$ & $5.12 \%$ & $2.68 \%$ & \multirow{2}{*}{\multicolumn{2}{|c|}{ No post hoc }} & \multirow{2}{*}{\multicolumn{2}{|c|}{ No correlation }} & \\
\hline Female & $27.53 \%$ & $28.98 \%$ & $31.47 \%$ & $7.82 \%$ & $4.18 \%$ & & & & & \\
\hline \multicolumn{11}{|l|}{ No. of children } \\
\hline None & $30.49 \%$ & $31.38 \%$ & $29.94 \%$ & $5.56 \%$ & $2.59 \%$ & \multirow{4}{*}{$\begin{array}{l}\text { None- Four or }+ \\
\text { One-Four or }+ \\
\text { Two-Four or }+ \\
\text { Three-Four or }+\end{array}$} & 0.205 & Tau-b Kendall & 0.042 & 0.000 \\
\hline \multirow{3}{*}{ Four or more } & $35.71 \%$ & $14.29 \%$ & $32.14 \%$ & $13.10 \%$ & $4.76 \%$ & & 0.535 & \multirow{3}{*}{ Rho Spearman } & \multirow[t]{3}{*}{0.048} & \multirow{3}{*}{0.000} \\
\hline & & & & & & & 0.617 & & & \\
\hline & & & & & & & 0.117 & & & \\
\hline \multicolumn{11}{|l|}{ Occupation } \\
\hline Student & $21.74 \%$ & $27.64 \%$ & $34.73 \%$ & $10.11 \%$ & $5.77 \%$ & \multirow{3}{*}{$\begin{array}{l}\text { Selt empl.-Hou. } \\
\text { Empl.-Unempl. }\end{array}$} & 0.281 & \multirow{2}{*}{\multicolumn{3}{|c|}{ No correlation }} \\
\hline Unemployed & $31.10 \%$ & $29.00 \%$ & $30.09 \%$ & $6.20 \%$ & $3.61 \%$ & & \multirow{2}{*}{0.065} & & & \\
\hline $\begin{array}{l}\text { Retired and } \\
\text { others }\end{array}$ & $33.60 \%$ & $32.47 \%$ & $28.31 \%$ & $3.44 \%$ & $2.13 \%$ & & & & & \\
\hline \multicolumn{11}{|c|}{ Household size } \\
\hline One & $32.78 \%$ & $32.44 \%$ & $28.28 \%$ & $4.31 \%$ & $2.20 \%$ & \multirow[t]{3}{*}{ One-Two } & \multirow[t]{3}{*}{0.337} & \multirow{3}{*}{$\begin{array}{l}\text { Tau-b Kendall } \\
\text { Rho Spearman }\end{array}$} & & \multirow{3}{*}{$\begin{array}{l}0.000 \\
0.000\end{array}$} \\
\hline Two & $32.03 \%$ & $32.39 \%$ & $27.89 \%$ & $5.30 \%$ & $2.35 \%$ & & & & \multirow[t]{2}{*}{0.102} & \\
\hline Six or more & $22.05 \%$ & $21.36 \%$ & $35.37 \%$ & $11.37 \%$ & $9.85 \%$ & & & & & \\
\hline
\end{tabular}

Source: Authors using data from [41].

Participants aged between 55-64 years old and over 65 years old had an especially negative feeling about advertising. Male participants found advertising especially annoying although both genders considered advertising to be irritating. Participants who lived in households without children and those with four or more children, as well as the unemployed and retirees also valued advertising negatively. Positive opinions, although with low percentages, were observed among the youngest participants, women, self-employed people, students, and those who did housework at home. Finally, households with five or six members also felt more positive about advertising.

When analyzing groups two by two, there were no significant differences between those aged 35-44 years old and those aged 45-54 years old. Likewise, no difference was observed between the participants aged between 55-64 years old and those over 65 years old. Significant differences were found between the participants with four or more children and other groups, between the self-employed and those who do housework, between employed people and the unemployed, and between households with one and two members. The correlations were marginally significant in all cases. A positive evaluation of advertising was only seen for the age variable.

\subsection{Post Hoc Test and Correlation for Use of Ad-Blockers}

A similar pos hoc analysis to the above was carried out for the use of ad-Blockers (see Table 7). Ad-blockers were frequently used by people aged 65 years old and older, and also by people between the ages of 14 and 24 . Women used ad-blockers more frequently 
than men. Furthermore, ad-blockers were also frequently used by respondents with two children, retired people, and those who do housework at home. Ad-blockers were also frequently used by the respondents living in households with four or more members. Adblockers were occasionally used by young people, participants with four or more children, and employed individuals. In contrast, blockers were not used by the group of people aged from 25 to 34 years old, people living in households without children, and by more than $30 \%$ of men. Correlations were not calculated, as the dependent variable is nominal.

Table 7. Use of ad-blockers for independent variables, 2019.

\begin{tabular}{|c|c|c|c|c|c|}
\hline Variable & Frequently & Occasionally & Does Not Use & KW Post Hoc & Value \\
\hline \multicolumn{6}{|l|}{ Age } \\
\hline $14-24$ & $51.58 \%$ & $19.05 \%$ & $29.38 \%$ & $14-24$ y $45-54$ & 0.315 \\
\hline $25-34$ & $39.80 \%$ & $19.55 \%$ & $40.65 \%$ & $14-24$ y $55-64$ & 0.184 \\
\hline More than 65 & $66.45 \%$ & $13.96 \%$ & $19.58 \%$ & $45-54$ y $55-64$ & 0.606 \\
\hline \multicolumn{6}{|l|}{ Gender } \\
\hline Male & $45.49 \%$ & $19.61 \%$ & $34.89 \%$ & & \\
\hline Female & $59.08 \%$ & $19.18 \%$ & $21.74 \%$ & & \\
\hline \multicolumn{6}{|l|}{ No children } \\
\hline None & $48.80 \%$ & $18.43 \%$ & $32.77 \%$ & None-Four or + & 0.840 \\
\hline Two & $53.60 \%$ & $21.60 \%$ & $24.80 \%$ & & \\
\hline Four or more & $46.43 \%$ & $26.19 \%$ & $27.38 \%$ & & \\
\hline \multicolumn{6}{|l|}{ Education } \\
\hline First grade & $59.23 \%$ & $18.13 \%$ & $22.64 \%$ & & \\
\hline University & $47.66 \%$ & $20.74 \%$ & $31.60 \%$ & & \\
\hline \multicolumn{6}{|l|}{ Ocupation } \\
\hline Self employed & $48.63 \%$ & $20.95 \%$ & $30.41 \%$ & Selfempl.-Empl. & 0.194 \\
\hline Employed & $47.51 \%$ & $20.59 \%$ & $31.90 \%$ & Selfempl.-Unempl. & 0.399 \\
\hline Housework & $61.89 \%$ & $19.42 \%$ & $18.69 \%$ & Empl.-Unempl. & 0.997 \\
\hline Retired and others & $60.28 \%$ & $14.18 \%$ & $25.54 \%$ & & \\
\hline \multicolumn{6}{|l|}{ Household size } \\
\hline One & $48.14 \%$ & $18.10 \%$ & $33.76 \%$ & One-Two & 0.542 \\
\hline Five & $52.64 \%$ & $21.76 \%$ & $25.60 \%$ & One-Three & 0.265 \\
\hline Six or more $(6)$ & $57.00 \%$ & $18.86 \%$ & $24.13 \%$ & & \\
\hline
\end{tabular}

\section{Discussion}

Most previous studies on the effect of different variables on how users feel about advertising have predominantly investigated age and gender. Other factors, such as the number of children in the household and occupation, have not often been considered. Therefore, the results of the present study increase knowledge about the subject and complement previous work. Li et al [51] found that some users considered programmatic advertising annoying. This has led to an increase in the use of ad-blockers that prevent this type of advertising from reaching the user [4]. However, the use of ad-blockers could be reduced if programmatic advertising manages to adapt to the demands of the users. The aim of this study was to find a way to minimize the negative effects of digital advertising, including programmatic advertising, by identifying which variables in the users' sociological profiles most affect the negative evaluation of this type of advertising.

The results suggest that gender and age greatly contribute to users' negative feelings about advertising, and these findings are consistent with those reported in previous studies $[33,34]$. Analyzing age showed that older people perceived advertising more negatively than younger people, which seems to contradict several previous studies [28,37]. In addition, there was an inverse, weak, yet significant correlation between these factors. In line with the results of [33], male respondents had a more negative opinion of programmatic advertising (see also [34,36]). The groups who valued programmatic advertising most negatively were the unemployed and retired, which contradicts the results of several other studies that reported that these negative feelings were given by respondents who were employed in companies [35,37]. The participants over 45 years old used ad-blockers most frequently, as did the youngest age group between 14 and 24 years old. This partially confirms the findings reported by [28]. 
The effect of the number of children, which had not been previously studied, gave inconclusive results. For the size of the household variable, it could be seen that the largest households gave positive evaluations. However, in both cases, the correlation was direct, weak and significant. Female participants used ad-blockers more frequently than males, which could be related to their negative feelings about advertising. The results for the effect of the number of children did not have a clear pattern, while the size of the household did seem to have a direct influence on users' feelings about advertising.

Finally, each user has individual personalities and experiences that may explain why they are willing to give up privacy in exchange for information. One possibility, using an indepth study such as this one, was proposed by Bačík et al. [37], where different advertising media were adapted to each user profile according to the results of previous studies. Other studies have investigated the increasingly widespread use of ad-blockers, which often only allow free downloading with premium-type payment options. An increasing number of users are willing to use them [33]. Some users may agree to allow information about their profiles to be collected so that the advertising they receive can be tailored to their own tastes, which is basically the same as programmatic advertising [4].

\section{Limitations and New Lines of Research}

The main limitation of this research is the territorial scope. This study was limited to Internet users who visited Spanish websites since the IACM is a Spanish agency that carries out audience studies in this country. However, a large sample was used, as explained in the methodology, and this allows conclusions to be confidently extrapolated, although cultural differences with Anglo-Saxon countries could affect the results to some extent. For this reason, a similar study in other countries is proposed as a new line of research, so that a transversal comparison can be made.

\section{Conclusions}

Most respondents feel that receiving a lot of advertising on the Internet is annoying. In the results of this study, it was seen that all sociological variables used in the study, except education, have a significant impact on the user feeling that advertising is annoying. Since companies use sociological and behavioral information to carry out advertising campaigns on the Internet, they should also be able to meaningfully use this type of sociological information to identify which users will use ad-blockers for cookies of programmatic advertising. Although ad-blockers are not widely used, most users know about them. Accordingly, all the sociological variables analyzed in this study were found to influence the use of ad-blockers.

An interesting finding was that there was a significant (albeit very marginal) correlation between feelings about advertising and the use of ad-blockers. Adults and women had a stronger negative view of advertising, and this made them use ad-blockers more. People who did not have a job rated advertising more negatively, which could be due to their more extensive use of the Internet for entertainment. Large households did not seem to take much notice of advertising, but they did use ad-blockers frequently. However, while small households found advertising annoying, they did not widely use ad-blockers, which seemed contradictory.

It is suggested that along with using sociological and behavioral information when preparing Internet advertising campaigns, companies should also use this information to identify the users which will use ad-blockers. The use of ad-blockers, due to the negative evaluation of advertising (among other factors) can provide important insights for computer engineers and technicians, as well as for marketing companies. The results of the present study can allow companies to identify which users will block their ads and, accordingly, learn to manage their resources more efficiently and effectively.

In future research, "wearable devices" should be included in the study. In addition, future studies could also use a binary logistic regression model to study different opinions about Internet advertising and the use of ad-blockers. 
Author Contributions: Conceptualization, E.R.-A.; Formal analysis, E.R.-A.; Methodology, P.R.P.-S.; Visualization, P.R.P.-S.; Writing-review \& editing, A.R.-M. All authors have read and agreed to the published version of the manuscript.

Funding: This research received no external funding.

Institutional Review Board Statement: Not applicable.

Informed Consent Statement: Not applicable.

Data Availability Statement: The database used in this study is public and has been obtained from this link https:/ / www.aimc.es/otros-estudios-trabajos/navegantes-la-red/.

Conflicts of Interest: The authors declare no conflict of interest.

\section{References}

1. Agrebi, S.; Jallais, J. Explain the intention to use smartphones for mobile shopping. J. Retail. Consum. Serv. 2015, 22, 16-23. [CrossRef]

2. Malloy, M.; McNamara, M.; Cahn, A.; Barford, P. Ad blockers: Global prevalence and impact. In Proceedings of the 2016 Internet Measurement Conference, Santa Monica, CA, USA, 14-16 November 2016; ACM: New York, NY, USA, 2016 ; pp. 119-125.

3. Murphy, M.; Sashi, C.M. Communication, interactivity, and satisfaction in B2B relationships. Ind. Mark. Manag. 2018, 68, 1-12. [CrossRef]

4. Palos-Sanchez, P.; Saura, J.R.; Martin-Velicia, F. A study of the effects of Programmatic Advertising on users' Concerns about Privacy overtime. J. Bus. Res. 2019, 96, 61-72. [CrossRef]

5. Palos-Sanchez, P.R.; Saura, J.R. The effect of internet searches on afforestation: The case of a green search engine. Forest 2018, 9, 51. [CrossRef]

6. Stourm, V.; Bax, E. Incorporating hidden costs of annoying ads in display auctions. Int. J. Res. Mark. 2017, 34, 622-640. [CrossRef]

7. Huang, Y. The female gaze: Content composition and slot position in personalized banner ads, and how they influence visual attention in online shoppers. Comput. Hum. Behav. 2018, 82, 1-15. [CrossRef]

8. Saura, J.R.; Reyes-Menendez, A.; Palos-Sanchez, P. Are Black Friday Deals Worth It? Mining Twitter Users' Sentiment and Behavior Response. J. Open Innov. Technol. Mark. Complex. 2019, 5, 58. [CrossRef]

9. Carrillo-Durán, M.V.; Rodríguez-Silgado, A. El ecosistema programático. La nueva publicidad digital que conecta datos con personas. El Prof. Inf. 2018, 27, 195-201. [CrossRef]

10. Li, W.; Huang, Z. The research of influence factors of online behavioral advertising avoidance. Am. J. Ind. Bus. Manag. 2016, 6, 947. [CrossRef]

11. Zambrano, A.; Pickard, C. A defense of ad blocking and consumer inattention. Ethics Inf. Technol. 2018, 20, 143-155. [CrossRef]

12. Newman, N.; Levy, D.A.; Nielsen, R.K. Reuters Institute Digital News Report Trackingthe Future News Reuters Inst. Study Journal. 2015. Available online: https://reutersinstitute.politics.ox.ac.uk/sites/default/files/2020-06/DNR_2020_FINAL.pdf (accessed on 28 November 2020).

13. Pujol, E.; Hohlfeld, O.; Feldmann, A. Annoyed users: Ads and ad-block usage in the wild. In Proceedings of the 2015 Internet Measurement Conference, Tokyo, Japan, 28-30 October 2015; pp. 93-106.

14. Iqbal, U.; Shafiq, Z.; Qian, Z. The ad wars: Retrospective measurement and analysis of anti-adblock filter lists. In Proceedings of the 2017 Internet Measurement Conference, London, UK, 1-3 November 2017; ACM: London, UK, 2017; pp. $171-183$.

15. dos Santos Rocha, R.; Fantinato, M. The use of software product lines for business process management: A systematic literature review. Inf. Softw. Technol. 2013, 55, 1355-1373. [CrossRef]

16. Burnham, J.F. Scopus database: A review. Biomed. Digit. Libr. 2006, 3, 1. [CrossRef] [PubMed]

17. Mongeon, P.; Paul-Hus, A. The journal coverage of Web of Science and Scopus: A comparative analysis. Scientometrics 2016, 106, 213-228. [CrossRef]

18. Hussain, R.; Ferdous, A.S.; Mort, G.S. Impact of web banner advertising frequency on attitude. Asia Pac. J. Mark. Logist. 2018, 30, 380-399. [CrossRef]

19. Wicker, S.B.; Karlsson, K. Internet advertising: Technology, ethics, and a serious difference of opinion. Commun. ACM 2017, 60, 70-79. [CrossRef]

20. Bell, R.; Buchner, A. Positive effects of disruptive advertising on consumer preferences. J. Interact. Mark. 2018, 41, 1-13. [CrossRef]

21. Braun, J.A.; Eklund, J.L. Fake News, Real Money: Ad Tech Platforms, Profit-Driven Hoaxes. Bus. J. Digit. J. $2019,7,1-21$.

22. Misugi, G.; Almendra Freitas, C.O.; Efing, A.C. Releitura da Privacidade Diante das Novas Tecnologias: Realidade Aumentada, Reconhecimento Facial e Internet das Coisas. Rev. Juríd. Cesumar-Mestr. 2016, 16, 427-453. [CrossRef]

23. Reyes-Menendez, A.; Saura, J.R.; Martinez-Navalon, J.G. The Impact of e-WOM on Hotels Management Reputation: Exploring TripAdvisor Review Credibility with the ELM Model; IEEE Access: Piscataeay, NJ, USA, 2019.

24. Tucker, C.E. Social networks, personalized advertising, and privacy controls. J. Mark. Res. 2013, 51, 546-562. [CrossRef]

25. Aguirre, E.; Mahr, D.; Grewal, D.; Ruyter, K.; Wetzels, M. Unraveling the personalization paradox: The effect of information collection and trust-building strategies on online advertisement effectiveness. J. Retail. 2015, 91, 34-49. [CrossRef]

26. Reyes-Menendez, A.; Saura, J.R.; Filipe, F. The importance of behavioral data to identify online fake reviews for tourism businesses: A systematic review. PeerJ Comput. Sci. 2019, 5, 219. [CrossRef]

27. Alaimo, C.; Kallinikos, J. Objects, Metrics and Practices: An Inquiry into the Programmatic Advertising Ecosystem. In Proceedings of the Working Conference on Information Systems and Organizations, San Francisco, CA, USA, 10-11 December 2018; Springer: Cham, Switzerland, 2018; pp. 110-123. 
28. Costa-Pérez, M.; Serrano-Puche, J.; Portilla-Manjón, I.; Sánchez-Blanco, M. Interacción de jóvenes adultos con noticias y publicidad online. Rev. Cientif. Iberoam. Comun. Educ. 2019, 59, 19-28.

29. Wills, C.E.; Uzunoglu, D.C. What ad blockers are (and are not) doing. In Proceedings of the 2016 Fourth IEEE Workshop on Hot Topics in Web Systems and Technologies HotWeb, Washington, DC, USA, 24-25 October 2016; IEEE: Piscataway, NJ, USA, 2016; pp. $72-77$.

30. Gugelmann, D.; Happe, M.; Ager, B.; Lenders, V. An automated approach for complementing ad blockers' blacklists. Proc. Priv. Enhancing Technol. 2015, 2015, 282-298. [CrossRef]

31. Antunes, D.C.; Maia, A.F. Big Data, ubiquitous exploitation, and targeted advertising: New facets of the cultural industry. Psicol. USP 2018, 29, 189-199. [CrossRef]

32. Redondo, I.; Aznar, G. To use or not to use ad blockers? The roles of knowledge of ad blockers and attitude toward online advertising. Telemat. Inform. 2018, 35, 1607-1616. [CrossRef]

33. Palos-Sanchez, P.; Martin-Velicia, F.; Saura, J.R. Complexity in the Acceptance of Sustainable Search Engines on the Internet: An Analysis of Unobserved Heterogeneity with FIMIX-PLS. Complexity 2018, 1-19. [CrossRef]

34. Hough, M.; Bae, Y.H.; Jun, J.W. Investigating consumer behavioural intention to utilise digital signage. Int. J. Internet Mark. Advert. 2016, 10, 255-269. [CrossRef]

35. Nhedzi, A. The relationship between traditional and digital media as an influence on generational consumer preference. Communitas 2018, 23, 18-38. [CrossRef]

36. Bačík, R.; Fedorko, R.; Rigelský, M.; Sroka, M.; Turáková, A. Perceiving the advertising in gender-generational characteristics. Pol. J. Manag. Stud. 2018, 18, 44-57. [CrossRef]

37. Punj, G. The relationship between consumer characteristics and willingness to pay for general online content: Implications for content providers considering subscription-based business models. Mark. Lett. 2015, 26, 175-186. [CrossRef]

38. Giovanis, A.N.; Binioris, S.; Polychronopoulos, G. An extension of TAM model with IDT and security/privacy risk in the adoption of internet banking services in Greece. EuroMed J. Bus. 2012, 7, 24-53. [CrossRef]

39. Roca, J.C.; García, J.J.; Vega, J.J. La importancia de la confianza percibida, la seguridad y la privacidad en los sistemas de comercio en línea. Gest. Inf. Segur. Inform. 2009, 17, 96-113.

40. Cho, Y.C.; Sagynov, E. Exploring factors that affect usefulness, ease of use, trust, and purchase intention in the online environment. Int. J. Manag. Inf. Syst. Online 2015, 19, 21. [CrossRef]

41. AIMC. Navegantes en Red; Survey; AIMC: Madrid, Spain, February 2020; Available online: https://www.aimc.es/otros-estudiostrabajos/navegantes-la-red/ (accessed on 28 November 2020).

42. Ibujes, M.O.; Tapia Zambrano, F.A. Interaprendizaje de Estadística Básica; Universidad Técnica del Norte: Ibarra, Ecuador, 2013.

43. Pedrosa, I.; Juarros-Basterretxea, J.; Robles-Fernández, A.; Basteiro, J.; García-Cueto, E. Pruebas de bondad de ajuste en distribuciones simétricas, ¿qué estadístico utilizar? Univ. Psychol. 2015, 14, 245-254. [CrossRef]

44. Camuffo, A.; Gerli, F. Modeling management behaviors in lean production environments. Int. J. Oper. Prod. Manag. 2018, 38, 403-423. [CrossRef]

45. Zhang, L.; Lu, W.; Liu, X.; Pedrycz, W.; Zhong, C. Fuzzy c-means clustering of incomplete data based on probabilistic information granules of missing values. Knowl. Based Syst. 2016, 99, 51-70. [CrossRef]

46. Remenova, K.; Skorkova, Z.; Jankelova, N. Span of Control in Teamwork and Organization Structure. Montenegrin J. Econ. 2018, 14, 155-165. [CrossRef]

47. Rivera-Trigueros, I.; Gutiérrez-Artacho, J.; Olvera-Lobo, M.D. Websites and Social Networks. A Study of Healthcare SMEs in Andalusia. In Proceedings of the International Conference on Information Technology \& Systems, Bogots, Colombia, 5-7 February 2020; Springer: Cham, Switzerland, 2020; pp. 297-306.

48. Roy-García, I.; Rivas-Ruiz, R.; Pérez-Rodríguez, M.; Palacios-Cruz, L. Correlación: No toda correlación implica causalidad. Rev. Alerg. Méx. 2019, 66, 354-360. [CrossRef]

49. Podsakoff, P.M.; MacKenzie, S.B.; Lee, J.Y.; Podsakoff, N.P. Common method biases in behavioral research: A critical review of the literature and recommended remedies. J. Appl. Psychol. 2003, 88, 879. [CrossRef]

50. Guo, Z.; Xiao, L.; Toorn, C.V.; Lai, Y.; Seo, C. Promoting online learners' continuance intention: An integrated flow framework. Inf. Manag. 2016, 53, 279-295. [CrossRef]

51. Liu, Z.; Min, Q.; Zhai, Q.; Smyth, R. Self-disclosure in Chinese micro-blogging: A social exchange theory perspective. Inf. Manag. 2016, 53, 53-63. [CrossRef] 